\title{
Evaluating the outcomes of a faculty capacity development programme on nurse educators in sub-Saharan Africa
}

\author{
J M van Wyk, ${ }^{1} \mathrm{PhD} ; \mathrm{J}$ E Wolvaardt, ${ }^{2} \mathrm{PhD} ; \mathrm{C}$ N Nyoni, ${ }^{3} \mathrm{PhD}$ \\ ${ }^{1}$ School of Clinical Medicine, College of Health Sciences, University of KwaZulu-Natal, Durban, South Africa \\ ${ }^{2}$ School of Health Systems and Public Health, Faculty of Health Sciences, University of Pretoria, South Africa \\ ${ }^{3}$ School of Nursing, Faculty of Health Sciences, University of the Free State, Bloemfontein, South Africa
}

Corresponding author: JM van Wyk(vanwykj2@ukzn.ac.za)

\begin{abstract}
Background. The efficient education, deployment and ongoing retention of the nursing and midwifery workforce are key strategies to ensure a wellfunctioning healthcare system. The African region, however, has relatively few funded programmes to develop educational research capacity in novice academics while also addressing their leadership and educational needs.

Objectives. To evaluate the outcomes of a faculty capacity development programme on nursing and midwifery educators in sub-Saharan Africa (SSA). This study explored the scope of scholarship outcomes, career trajectories and leadership outcomes.

Methods. A mixed methods study collected quantitative and qualitative data from nursing and midwifery educators $(N=26)$ who enrolled for the subSaharan Africa-FAIMER Regional Institute (SAFRI) fellowship between 2009 and 2019. Data from project abstracts presented at a local conference and a subsequent electronic survey were included for review and analysis. Deductive thematic analysis was used to report the findings.

Results. Most projects $(n=24)$ focused on undergraduate programmes at the home institutions. All the projects were presented at a local conference and 4 projects were published in peer-reviewed journals. The projects impacted on community and curriculum change, led to improvements in teaching and research and various strategies to improve learning and assessment at home institutions. The reported outcomes relating to the career trajectories of 7 fellows indicate that the programme accrued benefits to their institutions and the community, to students and their peers, and that they experienced personal benefits.

Conclusion. The SAFRI fellowship vision is evident in the projects and subsequent actions of its nursing and midwifery fellows. Nurse educators' engagement with pedagogical evidence and design strategies has culminated in knowledge to solve some of the education-related challenges in their nursing education institutions.
\end{abstract}

Afr J Health Professions Educ 2020;12(4):201-205. https://doi.org/10.7196/AJHPE.2020.v12i4.1389

Nurses and midwives contribute $\sim 66 \%$ of the health workforce in Africa, ${ }^{[1]}$ and are usually the first, and often the only, health professionals to be accessed by members of their communities. ${ }^{[2]}$ The efficient education, successful deployment and ongoing retention of the nursing and midwifery workforce are key strategies to ensure a well-functioning healthcare system aimed at the ultimate goal of universal health coverage. ${ }^{[3,4]}$ However, regional and international indicators reflect a protracted shortage of nurses and midwives in the healthcare system. ${ }^{[5]}$ An estimated additional 5.7 million nurses are required to meet the health needs of the global population by $2030 .{ }^{[1]}$

The need for more nurses correlates with the need to improve the numbers and quality of nurse educators, especially in Africa, where there is a substantive need. ${ }^{[6]}$ African literature describes the quantity, quality and competences of nurse educators in nursing education institutions (NEIs). In particular, Seekoe ${ }^{[7]}$ reports the needs of newly appointed nurse educators in South African (SA) universities and colleges regarding teaching, research, community engagement and work ethic. These needs may be similar throughout many African settings and influence the quality of nursing education. Consequently, nursing education stakeholders, such as the World Health Organization (WHO), have called for greater investments in nursing and midwifery education, strengthening of educational infrastructure and upskilling of nurse educators to ensure increased graduation outputs. ${ }^{[8]}$
The adoption of recognised continuing professional development (CPD) programmes and their relationship with licensure in many African countries have improved opportunities for upskilling of nurse educators. ${ }^{[9]}$ However, evidence suggests that the mainstream CPD programmes for nurses and midwives, including educators, focus on clinical practice and have limited content related to pedagogy, scholarship and leadership. ${ }^{[10]}$ The lack of capacity development programmes that are tailored to the needs of nurse educators, inadequate numbers of qualified nurse educators, ${ }^{[11]}$ and lack of self-directedness among nurse educators in Africa ${ }^{[12]}$ compromise the quality of nursing education and consequently the competencies of graduates of nursing programmes. Nurse educators need opportunities to engage with pedagogical evidence and design strategies to solve educationrelated challenges in their NEIs.

Not only are there relatively few funded programmes to upskill nurse and health educators comprehensively for leadership and academic duties, but there are also few programmes in the sub-Saharan African (SSA) region that provide individualised mentoring in educational research to ensure successful project completion. Condell and Begley ${ }^{[13]}$ define research capacity development as 'a funded, dynamic intervention operationalised through a range of foci and levels to augment the ability to carry out research or achieve objectives in the field of research over the long-term, with aspects 
of social change as an outcome'. A more recent definition by Willis et al. ${ }^{[14]}$ captures the complexities for those wishing to evaluate the impact of such interventions by highlighting that 'purposefully coordinated components of a research development programme could be targeted at multiple levels of a system, that may operate independently and interdependently in the contexts within which the components are implemented'.

In terms of measuring the success of capacity development programmes, we therefore embrace Cooke's ${ }^{[15]}$ notion of the futility of applying only traditional outcome measures, such as 'successful grant applications and publications in peer-reviewed journals' as indicators of success. The processes and products are indicators of success - recognising novice academics as researchers who often need to create or join suitable institutional environments for research and collaboration after developing the necessary skills and confidence to conduct independent research. This research uses Cooke's framework to guide readers to assess whether: (i) the intervention aided in the development of new skills/confidence; (ii) the intervention was supported through partnerships/networks; (iii) the research was undertaken close to the coalface of the practitioner; (iv) the capacity programme supported or advanced appropriate dissemination of findings; $(v)$ there was any contextual investment in infrastructure; and $(v i)$ the programme contained elements of sustainability and continuity. ${ }^{[15]}$

\section{The SAFRI fellowship programme: A vehicle for capacity development in SSA} The sub-Saharan Africa-FAIMER Regional Institute (SAFRI) offers a faculty and research capacity building programme that is delivered via an integrated residential and distance-learning format. The 2-year programme focuses on developing leadership, project management and programme evaluation skills in health professions education while a fellow engages in an educational research project based on a problem identified at their home institution. SAFRI fellows also engage with key principles of health professions education, such as curriculum design, assessment, teaching and learning, while being guided in the design and implementation of an education innovation project. ${ }^{[16]}$ They are furthermore supported to develop appropriate scholarship skills by presenting their findings in the form of a poster presented to the SAFRI community, and presenting orals/posters at a national peer-reviewed conference, as well as being encouraged to submit a research report for publication in a peer-reviewed journal. The programme recently celebrated its 10th anniversary with $>180$ health professionals from 23 African countries, including nurses and midwives who graduated successfully as fellows. ${ }^{[17]}$ Given the 10 -year milestone and the relative absence of similar capacity development programmes in the region, this study was conducted to review the outcomes of the SAFRI programme on educational programmes and personal achievements of fellows representing nursing and midwifery.

\section{Purpose of this study}

This paper describes the outcomes of a faculty capacity development programme (SAFRI) on nursing and midwifery educators in SSA.

The objectives were to:

- describe the demography of nurse educators who graduated from the SAFRI fellowship

- provide a thematic overview of the types of educational innovation projects conducted by nurse educators who graduated from the SAFRI fellowship
- describe the scholarship outcomes of nurse educators who graduated from the SAFRI fellowship

- describe the career trajectories and leadership outcomes of nurse educators who graduated from the SAFRI fellowship.

\section{Methods \\ Research design}

This study was executed through a parallel convergent mixed methods design applying both quantitative and qualitative methods. ${ }^{[18]}$

\section{Population and sampling}

The study population comprised 26 nursing and midwifery educators, practitioners or managers who graduated between 2009 and 2019 from the SAFRI fellowship. All the fellows had to have been engaged with a nursing or midwifery education-related project during the fellowship. Census sampling was used to include all the nurses and midwives as participants in this study. All abstracts related to nursing and midwifery education presented at a local conference by the 26 fellows were included for review and analysis. Subsequently, all the fellows were contacted by email explaining the purpose of the study and inviting them to complete an electronic survey.

\section{Data collection}

Data were collected through two parallel methods aligned with the overarching research design. Qualitative data were extracted from the abstract booklets of a local conference. The data were collated on a data extraction sheet that focused on the country of origin, research design, focus of the study, issues of contention, summary of the main findings and take-home message. ${ }^{[19]}$ The authors individually extracted data from each abstract and discussed the outcomes thereof. Discrepancies were resolved through discussion to reach consensus. The collected data were entered into an Excel spreadsheet (Microsoft, USA) to facilitate thematic synthesis. ${ }^{[20]}$

A researcher-developed survey that explored the career trajectories, leadership outcomes and postgraduate scholarship outcomes was administered to the participants $(N=26)$ using online SurveyMonkey software.

\section{Data analysis}

Data were analysed to address each of the objectives of the study. Thematic synthesis according to Braun and Clarke ${ }^{[20]}$ informed the analysis of the qualitative data. Thematic synthesis aligns with the analysis of secondary qualitative data and is executed in three sequential steps. The initial step focused on line-by-line coding of the extracted data. This process was engaged by each of the researchers independently to generate a list of 'free' codes emanating from the data. The second step aimed at inductively organising the free codes to generate descriptive themes. In this step, the free codes were grouped based on similarities and alignment to generate the descriptive themes. The final step focused on the development of analytical themes, which were an outcome of contesting and clustering the descriptive codes against the research objectives. ${ }^{[20]}$

\section{Ethical approval}

This study was approved by the Human and Social Sciences Research Ethics Committee of the University of KwaZulu-Natal (UKZN) (ref. no. HSSREC/00001238/2020). The chief executive officer of the SAFRI company 
granted permission to access fellowship-related data. All participants included in the study consented to participate. Ethical considerations, such as voluntary participation, informed consent, privacy and confidentiality, were taken into account throughout the study.

\section{Results}

The data extracted from the abstract books represent the work of $14 \%$ of all completed SAFRI projects $(N=184)$. Projects conducted by female and male fellows represented $77 \%(n=20)$ and $23 \%(n=6)$ of the sample, respectively. Nineteen of the included studies used qualitative research designs, 4 employed mixed method designs and 3 used quantitative methodologies. The majority of fellows were from Lesotho (Table 1).

Four analytical themes (Table 2; http://ajhpe.org.za/public/files/1389-2.pdf) were identified in response to the objective that sought to describe the nature and scope of the educational research projects conducted by the nursing/ midwifery fellows during the SAFRI fellowship. Most studies $(n=24)$ focused on undergraduate programmes. The analytical themes include: impact on the community; impact on curriculum change; improving teaching and research; and improving learning and assessment.

While the analysis of the abstracts provided insight into the shortterm outcomes of the educational projects and the concerns of the nurse educators who completed the SAFRI fellowship, the data from 7 completed questionnaires were analysed to establish longer-term career trajectories and leadership and scholarship outcomes of the nursing and midwifery fellows. This analysis resulted in 4 new themes:

- theme 1: professional benefit

- theme 2: personal and peer benefit

- theme 3: student benefit

- theme 4: institutional and community benefit.

\section{Theme 1: Professional benefit}

The participants reported acquiring an increasing number of educationrelated roles and responsibilities after completion of the fellowship. Specific examples were: heading of departments, leading education-related research projects and driving faculty development initiatives:

'Yes, as head of the programme I was responsible for the strategic leadership of a nursing programme, planning and budgeting for teaching and learning for the programme, mentoring junior staff, quality assurance and improvement activities.' (Fellow 3)

In their new roles, participants were able to develop curricula and a variety of educational materials for their programmes:

Table 1. Country where the educational projects were conducted

\begin{tabular}{ll}
\hline Country & $\%(\boldsymbol{n})$ \\
\hline Lesotho & $31(8)$ \\
South Africa & $27(7)$ \\
Kenya & $15(4)$ \\
Uganda & $15(4)$ \\
Botswana & $4(1)$ \\
Namibia & $4(1)$ \\
Zambia & $4(1)$ \\
Total & $100(26)$
\end{tabular}

'During project implementation, I used the competence I acquired on faculty development to develop a curriculum on student performance assessment incorporating construction items, measurement, criterionreferenced pass score, item blueprinting, item analysis, item bank etc. for nursing, midwifery and clinical officer faculty.' (Fellow 1)

\section{Theme 2: Personal and peer benefit}

The participants noted improved interpersonal relationships and collaboration with other SAFRI fellows from either their home institutions or internationally. Some of this collaboration included academic support:

'Reviewing fellows' data collection tool; participating in fellows' predefending of proposal; supporting someone to apply for the fellowship; develop academic programmes and design education-related projects.' (Fellow 2)

Peers also clearly benefited from the activities of the fellows:

'I have used the knowledge and skill related to research and have conducted research projects with colleagues in the institution. I have been able to use the knowledge and skills related to teaching, learning, and assessments in the faculty development activities for newly recruited faculty in our institution. I conduct refresher workshops on assessment for colleagues prior to summative assessments every semester. The knowledge about the management of self and other has always been handy in the day to day activities and as tips to colleagues.' (Fellow 4)

'I have been able to use some of the findings from the project in my own mentoring activities with other faculty, both old and new.' (Fellow 6)

Participants reflected that these collaborations improved their participation in scholarly activities, such a conferences, and reported completing further studies such as Master's or doctoral degrees.

\section{Theme 3: Student benefit}

Students also reportedly benefited by having these SAFRI fellows as educators. The benefits were directly related to their educational projects during the fellowship and the educational programme of the SAFRI fellowship, such as improved support for student learning, authentic teaching approaches and eagerness of students to engage with their clinical environment:

'The SAFRI project has helped improve the support of students. Some aspects of the SAFRI project are embedded in the learning approaches for students. The revised curriculum requires students to engage in co-operative learning as they engaged in group activities. I have been able to develop better learning activities and study guides for students, leading to better learning experiences. There has also been the introduction of other student support strategies such as tutorials at the institutions.' (Fellow 6)

The problem-solving skills acquired during the fellowship enabled participants to procure appropriate resources for learning:

'The students needed equipment for screening of clients during home visits, so we developed a bag with blood pressure machines for checking blood pressure and also glucometers for checking glucose levels. The community members were participating and fully involved especially in changing their lifestyle. Now that we have the equipment even the 
students were motivated and participating fully during home visits. (Fellow 5)

Participants shared numerous other examples of how they could apply their educational expertise, such as revision of assessment programmes, integration of objective structured clinical examinations (OSCEs) within the assessment strategy, and simulation-based education.

\section{Theme 4: Institutional and community benefit}

Participants reported broader institutional effect, such as a greater recognition of health professions education and institutional cyclic efforts associated with curriculum change, and more nurses were supported to apply for the SAFRI Fellowship:

'There are institutionalised approaches to cyclical revision and development of curricula in the country. The educational bodies are beginning to recognise the role medical education systems can play in improving outcomes of educational programmes.' (Fellow 1)

Some reported investment in expanded opportunities for faculty development for all nurses, which is usually led by SAFRI fellows:

'More faculty development activities for institutional staff and members from other institutions. More research output from the institution other than that related to SAFRI and academic achievements. The institution SAFRI fellows spearheaded curricular reviews and designed assessment of programmes for the two programmes offered at the institution. The institution SAFRI members spearheaded the quality assurance committee and helped the accreditation of all the programmes offered.' (Fellow 6)

The effect of the fellowship extended beyond the institution, as one of the nursing departments was formally recognised for excellence in community engagement:

'The Department of Nursing was awarded with the Vice-Chancellor Excellence award in Community Engagement from the University. (Fellow 5)

A second example was where efforts to engage nurses in clinical practice environments to support nursing students while on rotation had been successful:

'There was more engagement of clinical staff in training of nurses as a result of the results and recommendations from the study. Clinical staff members are now more engaged in student placement planning and clinical assessments. Moreover, more preceptorship training has been lined up and budgeted for as a result of the study'. (Fellow 3)

Participants also contributed to the nursing and midwifery community at national levels:

'Membership of important national decision-making bodies.' (Fellow 2)

\section{Discussion}

This study explored the outcomes of the SAFRI capacity development programme on educational research projects and personal achievements of nursing and midwifery SAFRI fellows. The actions of the fellows in both the short and long term confirm the intended outcome of the fellowship with regard to community effect, and reflect Cooke's assertion that each principle can affect the individual, team or organisational level. ${ }^{[15]}$ Both the projects and subsequent actions supported the philosophy of meeting key stakeholders' needs - those of the patient and community being paramount. In some cases, this community focus was rewarded by formal recognition within an institution. Formal recognition for community work is an important aspect of ensuring continuity and sustainability of projects, thereby meeting the sixth principle in Cooke's framework. ${ }^{[15]}$

While all the projects originated from an identified problem at the fellows' home institution (Table 2; http://ajhpe.org.za/public/files/1389-2.pdf), it was rewarding that the projects had an effect at varying levels. Some of the projects resulted in policy and practice changes at community level, whereas others were conducted in institutions where curricular changes could best be negotiated. The most rewarding aspect was that all the reported projects satisfied Cooke's criterion of having engaged in research close to the coalface. ${ }^{[15]}$

A noticeable and common remark from the personal and career data indicates the engagement and involvement of fellows in leadership, academic and research activities after completion of the fellowship. This continued engagement included taking the lead in faculty development workshops, presenting their projects at national conferences and mentoring others at their institutions. These activities indicate the personal and professional growth and substantial skill and confidence developed during their engagement with supportive networks - Cooke's second principle. ${ }^{[15]}$

Evidence suggests that research skills development ultimately increases research activity ${ }^{[21]}$ and results in positive attitudes towards research collaboration, ${ }^{[22]}$ while a lack of research training is a barrier to doing research. ${ }^{[23]}$ While only 4 fellows in the current cohort reported having reworked their SAFRI projects into publications, all 26 fellows had presented their findings at the national conference - an appropriate platform to disseminate results. ${ }^{[15]}$ The 7 qualitative reports indicated that the fellows continue to engage and collaborate in further educational research. Some of this continued research has culminated in formal qualifications, such as Master's and $\mathrm{PhD}$ degrees.

Many of the projects and subsequent interventions appear to also have benefited the NEIs and colleagues. Institutional benefit included the formation of local networks that drove improved educational practice of educators, the introduction of a wide range of new teaching and assessment strategies, as well as fellows engaging in faculty development activities. Participants were also concerned about ensuring the quality of the teaching and learning and the student experience. The focus of the majority of the projects and subsequent actions has been to improve the curricula and the current teaching and assessment strategies in terms of content, choice of educational material and clinical skills. The formation of home teams suggests that fellows had used the experience gained to build new alliances in their NEIs, thus ensuring some continuity of their gains. Other fellows have identified like-minded junior academics to coach into SAFRI fellowship, thus forming local and sustainable networks. These data reflect several of Cooke's principles at an individual, team and organisational level. ${ }^{[15]}$

The notion of stepping outside of a safety zone may also suggest increased confidence and ability to do research. ${ }^{[15]}$ This may be illustrated at an individual level by the practitioner-researcher taking on managerial roles, supervising others, or tackling new methodologies/approaches in research, or working with other groups of health and research professionals on research projects. This approach is supported by the model of research 
capacity building suggested by Farmer and Weston ${ }^{[24]}$ to indicate one's progress and participation through to academic leadership.

Many of the reported faculty development activities were aligned with strengthening the teaching and assessment competence of educators employed by the NEIs. Some of the projects (and subsequent actions) also extended the notion of educator to nurses and midwives in clinical settings. The concept of supporting education competencies of nurses and midwives in the clinical environment is essential, but receives little attention. ${ }^{[25]}$ Some of the projects focused on responding to change, and even though this aspect did not emerge in the survey, the COVID-19 pandemic has certainly forefronted this need.

\section{Conclusion}

The SAFRI fellowship has a specific vision that finds form and structure in the actions of its fellows. This study confirms that the vision has been fulfilled by the projects and subsequent actions of its nursing and midwifery fellows. It is clear that these fellows as nurse educators have used the fellowship opportunity to engage with pedagogical evidence and design strategies, and have applied this knowledge to solve some of the educationrelated challenges in their NEIs.

\section{Declaration. None.}

Acknowledgements. The authors would like to acknowledge the SAFRI management for permitting this study and the SAFRI fellows who participated in the study.

Author contributions. All authors contributed to the conception, design, development and execution of this study.

Funding. None.

\section{Conflicts of interest. None.}

\footnotetext{
1. World Health Organization. State of the World's Nursing 2020: Investing in Education, Jobs and Leadership. Geneva: WHO, 2020

2. Nyoni $\mathrm{CN}$, Botma Y. Sustaining a newly implemented competence-based midwifery programme in Lesotho: Emerging issues. Midwifery 2018;59:115-117. https://doi.org/10.1016/j.midw.2018.01.015
}

3. Shalala D, Bolton L, Bleich M, Brennan T, Campbell R, Devlin L. The Future of Nursing: Leading Change, Advancing Health. Washington DC: National Academy Press, 2011.

4. Frenk J, Chen L, Bhutta ZA, et al. Health professionals for a new century: Transforming education to strengthen health systems in an interdependent world. Lancet 2010;376(9756):1923-1958. https://doi.org/10.1016/S0140 6736(10)61854-5

5. World Health Organization. Global Strategy on Human Resources for Health: Workforce 2030. Geneva: WHO, 2016

6. Bvumbwe T, Mtshali N. Nursing education challenges and solutions in Sub-Saharan Africa: An integrative review. BMC Nurs 2018;17(1):3. https://doi.org/10.1186/s12912-018-0272-4

7. Seekoe E. Competence developmental needs of newly appointed nurse educators during the mentoring process. Seekoe E. Competence developmental needs of newly ap

8. Campbell J, Dussault G, Buchan J, et al. A Universal Truth: No Health without a Workforce. Geneva: WHO, 2013

9. Hosey KN, Kalula A, Voss J. Establishing an online continuing and professional development library for nurses and midwives in East, Central and Southern Africa. J Ass Nurse AIDS Care 2016;27(3):297-311. https://doi. org/10.1016/j.jana.2016.01.007

10. Feldacker C, Pintye J, Jacobs S, et al. Continuing professional development for medical, nursing and midwifer cadres in Malawi, Tanzania and South Africa: A qualitative evaluation. PLoS ONE 2017;12(10):e0186074.

11. Asamani JA, Amertil NP, Ismaila H, Francis AA, Chebere MM, Nabyonga-Orem J. Nurses and midwives demographic shift in Ghana - the policy implications of a looming crisis. Hum Resource Health 2019;17(1):1-5

12. Van Rensburg GH, Botma Y. Bridging the gap between self-directed learning of nurse educators and effective student support. Curationis 2015;38(2):1503. https://doi.org/10.4102/curationis.v38i2.1503

13. Condell SL, Begley C. Capacity building: A concept analysis of the term applied to research. Int I Nurs Pract 2007;13(5):268-275. https://doi.org/10.1111/j.1440-172X.2007.00637.x

14. Willis C, Riley B, Lewis M, Stockton L, Yessis J. Guidance for organisational strategy on knowledge to action from conceptual frameworks and practice. Evidence Policy 2017;13(2):317-341.

15. Cooke J. A framework to evaluate research capacity building in health care. BMC Fam Pract 2005;6(1):44.

16. Frantz JM, Bezuidenhout J, Burch VC, et al. The impact of an educational faculty development programme for health professionals in sub-Saharan Africa: An archival study. BMC Med Educ 2015;15(28):3-9. https://dol org/10.1186/s12909-015-0320-7

17. Sub-Saharan Africa-FAIMER Regional Institute (SAFRI). 10th Year Anniversary Photo Book. 2018. https://www. yumpu.com/en/document/view/60848567/10th-year-anniversary-photo-book (accessed 20 August 2020).

18. Creswell JW, Clark VLP. Designing and Conducting Mixed Methods Research. Thousand Oaks, CA: SAGE, 2017.

19. Munn Z, Tufanaru C, Aromataris E. JBI's systematic reviews: Data extraction and synthesis. Am J Nurs 2014;114(7):49-54. https://doi.org/10.1097/01.NAJ.0000451683.66447.89

20. Braun V, Clarke V. Reflecting on reflexive thematic analysis. Qual Res Sport Exerc Health 2019;11(4):589-597. Braun V, Clarke V. Reflecting on reflexive them
https://doi.org/10.1080/2159676X.2019.1628806

21. Schmidt DD, Webster E, Duncanson K. Building research experience: Impact of a novice researcher development program for rural health workers. Aust J Rural Health 2019;27(5):392-397. https://doi.org/10.1111/ajr.12520

22. Kotecha P, Walwyn D, Pinto C. Deepening research capacity and collaboration across universities in SADC: A Southern African universities regional research and development fund. 2011. https://www.academia.edu/ download/53557890/Deepening_Research_Capacity_and_Collabor20170617-2773-5scbod.pdf (accessed 20 August 2020).

23. Verhoef MJ, Mulkins A, Kania A, Findlay-Reece B, Mior S. Identifying the barriers to conducting outcomes research in integrative health care clinic settings - a qualitative study. BMC Health Serv Res 2010;10(1):14 https://doi.org/10.1186/1472-6963-10-14

24. Farmer E, Weston KM. A conceptual model for capacity building in Australian primary health care research. Aust Fam Phys 2002;31(12):1139.

25. Rebeiro G, Evans A, Edward K, Chapman R. Registered nurse buddies: Educators by proxy? Nurse Educ Today 2017;55:1-4. https://doi.org/10.1016/j.nedt.2017.04.019

Accepted 25 August 2020 